\title{
Detection Efficiency of a Nal(TI) Gamma Spectrometry System for Measurement of Low Level Radioactivity
}

\author{
Biere $\mathbf{P}$ Ebibuloami ${ }^{1}$, Ogunremi Ayorinde ${ }^{2}$, Aina J Oluwagbenga ${ }^{3}$, Emumejaye \\ Kugbere $^{4}$, Olaoye M Adeola ${ }^{5}$ and Mustapha A Olalekan ${ }^{3}$ \\ ${ }^{1}$ Department of Physics, Niger Delta University, Wilberforce Island. Bayelsa State, Nigeria \\ ${ }^{2}$ Department of Science Laboratory Technology, Yaba Collee of Technology, Lagos State, Nigeria \\ ${ }^{3}$ Department of Physics, Federal University of Agriculture Abeokuta, Ogun State, Nigeria \\ ${ }^{4}$ Department of Science Laboratory Technology, Delta State Polytechnic, Ozoro, Delta State, Nigeria \\ ${ }^{5}$ Department of Physics, Lagos State University, Lagos State, Nigeria
}

Corresponding E-mail: pbiere2003@gmail.com

Received 25-06-2021

Accepted for publication 16-08-2021

Published 06-09-2021

\begin{abstract}
Qualitative analysis of radionuclides requires the use of reliable gamma-ray detection system. The $\mathrm{NaI}(\mathrm{Tl})$ detector has been widely used and still one of the most used detectors today. It is therefore imperative to validate the reliability of the $5 \times 5 \mathrm{~cm}^{2} \mathrm{NaI}(\mathrm{Tl})$ gamma spectrometry system used in carrying out gamma-ray analysis of soil samples in the Radiation and Health Laboratory, Federal University of Agriculture Abeokuta, Nigeria. The gamma ray spectrometer is housed in a $5 \mathrm{~cm}$ thick cylindrical lead shield. Calibration was executed using standard materials produced under the auspices of the International Atomic Energy Agency (IAEA). Resolution and detection limit $\left(\mathrm{L}_{\mathrm{D}}\right)$ of the detector were determined using full width at half the maximum of the energy peak of ${ }^{137} \mathrm{Cs}$ and background signal level of the reference materials respectively. Counting efficiencies of the detector was calculated using energies of $1460 \mathrm{keV}$, $1764 \mathrm{keV}$ and $2615 \mathrm{keV}$ for ${ }^{40} \mathrm{~K},{ }^{226} \mathrm{Ra}$ and ${ }^{232} \mathrm{Th}$ respectively. Secondary samples, RGMIX1 and RGMIX2 were formulated and counted to calculate activity concentrations using the $\mathrm{NaI}(\mathrm{Tl})$ detector. Resolution of the detector was calculated to be $7.8 \%$ of ${ }^{137} \mathrm{Cs}$, which is good for a $\mathrm{NaI}(\mathrm{Tl})$ detector. The counting efficiency of the detector is seen to depend on the gamma ray energy. The results from this work shows that the detector system is suitable gamma spectrometry, and will give quality measurements when used for quantitative determination of radionuclides in environmental samples. The efficiency and resolution of the $\mathrm{NaI}(\mathrm{Tl})$ detector should also be determined using photon energies obtained from other radioactive sources.
\end{abstract}

Keywords: Radionuclides; Gamma spectrometer; Calibration; Resolution; Activity concentration; Counting efficiency

\section{INTRODUCTION}

$\mathrm{T}$ errestrial radiation has been around since the creation of the earth's crust. It is found in rocks, soil, air, water and vegetation [1]. Human beings are always in contact with the sources of terrestrial radiation. Therefore, it is important to measure the level of radiation in the environment to ascertain how much they affect our daily lives [2]. In doing this, correct, proper and reliable methods and equipment should be used. The detection and quantification of radionuclides 
available in a source depends on the detection of gamma photon energy and the relative abundance of photons. Qualitative analysis of radionuclides in materials requires the use of reliable gamma-ray detection system. The detection of gamma rays most importantly depends upon the gamma ray photon undergoing an interaction that transfers all or part of the photon energy to an electron in the absorbing material [3; $4 ; 5]$. Therefore, for a detector to be used in gamma ray spectrometry, the detector must act as a medium of conversion where incident gamma rays have a high probability of interacting to yield more fast electrons and equally act as a detector for the secondary electrons produced. The $\mathrm{NaI}(\mathrm{Tl})$ is an inorganic scintillation detector that was discovered by Robert Hofstadter in 1948 [6; 7]. It uses crystals that emit light when gamma rays interact with the atoms in the crystal. Though there are crystals of several organic and inorganic compounds which can exhibit this phenomenon but not all are however suitable for use as detectors. One face of the detector is free while the other is optically coupled to a photomultiplier tube which detects the small visible light photons produced in the crystal and converts them into amplified electrical pulses which can be fed into suitable analyzer systems. To improve the probability of visible photon emission, small amounts of an impurity or "activator" such as thallium (T1) are commonly added to the inorganic scintillator [8]. Sodium iodide thallium activated $(\mathrm{NaI}(\mathrm{Tl}))$ is an impurity activated inorganic crystal which has unique suitability in gamma-ray measurement [7]. Other examples are $\mathrm{CsI}(\mathrm{Tl}), \mathrm{LiI}(\mathrm{Tl})$ and $\mathrm{CaF}(\mathrm{Eu}) . \mathrm{NaI}(\mathrm{T} 1)$ has the highest light yield of all known scintillation materials $[9 ; 8 ; 10)$. It has a linear response to electrons and gamma rays. The $\mathrm{NaI}(\mathrm{Tl})$ has been widely used since the beginning of gamma spectroscopy and it is still one of the most used detectors today. This is not only because of the fact that it is a relatively economical detector, but also because the spectrometry systems based on $\mathrm{NaI}(\mathrm{Tl})$ detectors perform faster analysis due to their high efficiency, and there are many configurations of $\mathrm{NaI}$ detectors available commercially. The disadvantage of the $\mathrm{NaI}(\mathrm{Tl})$ is its lower resolution [11]. However, with special attention, the spectrum windows for measuring the radionuclide activity can be defined. Although, NaI(T1) can be easily structured into required sizes and shapes, it is fragile and can be easily damaged through mechanical and thermal shocks $[12 ; 9 ; 10]$. $\mathrm{NaI}(\mathrm{T} 1)$ is also hygroscopic, it therefore, has to be encapsulated inside a hermetically sealed casing usually of aluminum which is thin enough to allow gamma radiation to pass through without significant attenuation [13; 14]. However, for quality and reliable results to be obtained, there is the need to ascertain the performance of the spectrometry system by ensuring that it is adequately calibrated with reliable standard calibration sources.

The purpose of this study is to validate the reliability of the $5 \times 5 \mathrm{~cm}^{2} \mathrm{NaI}(\mathrm{Tl})$ gamma spectrometry system used in carrying out Gamma-ray spectrometry analysis of soil samples in the Radiation and Health Laboratory, Department of Physics, Federal University of Agriculture Abeokuta, South Western Nigeria.

\section{MATERIALS AND METHODS}

\section{A. $\mathrm{NaI}(\mathrm{Tl})$ gamma ray spectrometer}

The gamma ray spectrometer used consists of a $5 \times 5 \mathrm{~cm}^{2}$ $\mathrm{NaI}(\mathrm{Tl})$ detector housed in a $5 \mathrm{~cm}$ thick cylindrical lead shield in the Multipurpose Physics Laboratory in the Federal University of Agriculture Abeokuta. It also comprises a combined Amplifier-Voltage supply. Data acquisition and analysis were performed with an ORTEC Multichannel Analyzer (MCA), Multichannel Buffer (MCB) and digiBASE. The digiBASE combines a miniaturized preamplifier and detector high voltage $(0 \mathrm{~V}$ to $+1200 \mathrm{~V}$ bias $)$ with a powerful digital multichannel analyzer and special features for fine time-resolution measurements [15]. The $\mathrm{NaI}(\mathrm{Tl})$ detector has a gain that is sensitive to changes in ambient temperature and magnetic fields. The digiBASE incorporates a gain stabilizer to significantly diminish this sensitivity. It works by monitoring the centroid of a designated peak in the energy spectrum; the fine gain is automatically and continuously adjusted to maintain the centroid of the peak at its desired position [16]. The digiBASE is supplied with a MAESTRO-32 MCA Emulation Software and the installation of the digiBASE is done with its USB connection. Installed are the accompanying CONNECTIONS-32 Driver Update Kit and MAESTRO-32 software. The digiBASE is connected to the USB port of the computer system used. MAESTRO-32 contains all the controls needed to adjust the acquisition parameters, acquire the data, and save the spectra.

\section{B. Standard samples and calibration of the gamma-ray spectrometer}

Energy and efficiency calibrations were carried out using standard materials which were produced under the auspices of the International Atomic Energy Agency (IAEA) and were distributed through its Analytical Control Services (AQCS) program. According to the manufacturers, RGU-1 was prepared from a dilution of Uranium ore (BL-5) with silica sand, RGTh-1 was prepared from a dilution of Britholite material (OKA-2) with silica sand, and RGK-1 was prepared from potassium Sulphate. The standard materials were put into the sample containers which were kept for about one month to achieve equilibrium between radium and its decay products [17]. They were then counted using the $\mathrm{NaI}(\mathrm{Tl})$ detector for $1800 \mathrm{~s}$, which was long enough to capture spectra with well resolved peaks. Three suitable energy peaks were selected. The calibration procedure continued by selecting the calculation option of the maestro digiBase software, calibration option was selected and the gamma energies of each of the peaks of interest were inserted against their channel numbers. A relation of the gamma energy versus channel number was established by the software then 
the channel numbers and the corresponding energy values were matched. The photopeaks used were $1460 \mathrm{keV}$, $1764 \mathrm{keV}$ and $2615 \mathrm{keV}$ for ${ }^{40} \mathrm{~K},{ }^{226} \mathrm{Ra}$ and ${ }^{232} \mathrm{Th}$ respectively. In order to convert the count rates (cps) response of the spectrometer to desirable activity in $\mathrm{Bq}$ for each radionuclide; ${ }^{40} \mathrm{~K},{ }^{226} \mathrm{Ra}$ and ${ }^{232} \mathrm{Th}$ in the sample, the three reference standard materials, RGU-1, RGUTh-1 and RGK-1 were counted and Region of Interest (ROI) was created.

\section{Resolution of the NaI(Tl) detector used}

Resolution is the detector's ability to resolve little alterations in the energy of incident photons [18]. It is defined quantitatively as the number of channels between the half maximum point in the photopeak divided by the channel number of the photopeak and multiplied by $100 \%$. The resolution of the detector was determined by dividing the number of channels between the half maximum point in the photopeak of ${ }^{137} \mathrm{Cs}$ by the channel number, $\mathrm{H}$ of the photopeak and multiplied by $662 \mathrm{keV}$. This is given by (1) for ${ }^{137} \mathrm{Cs}$.

$$
R=\frac{\Delta X}{H} \times 662 \mathrm{keV}
$$

Where: $\mathrm{R}=$ resolution, $\Delta \mathrm{X}=\mathrm{X} 2-\mathrm{X} 1=\mathrm{FWHM}$ (full width at half maximum), $\mathrm{H}=$ centroid channel.

\section{Efficiency calibration}

This was necessary in order to convert the count rates (cps) response of the spectrometer to desirable activity in $\mathrm{Bq}$ for each radionuclide; ${ }^{40} \mathrm{~K},{ }^{226} \mathrm{Ra}$ and ${ }^{232} \mathrm{Th}$ in the sample. The three reference standard materials, RGU-1, RGUTh-1 and RGK-1 were counted and Region of Interest (ROI) was created. Counting efficiencies were calculated and recorded for all gamma transitions with appreciable emission probabilities in both ${ }^{226} \mathrm{Ra}$ and ${ }^{232} \mathrm{Th}$ decay series and the $1460 \mathrm{keV}$ of $40 \mathrm{~K}$ using the relation in (2) [19].

$$
\varepsilon_{I}\left(E_{i}\right)=\frac{n_{S}-n_{B}}{P_{I}\left(E_{i}\right) \text { C. } m_{S}}
$$

Where: $\varepsilon_{I}\left(E_{i}\right)$ is absolute counting efficiency of gamma energy $\left(E_{i}\right)$ (counts $\left.\mathrm{sec}^{-1} \mathrm{~Bq}^{-1}\right), n_{s}$ is count rate in a particular energy window with filled containers (counts $\sec ^{-1}$ ), $n_{B}$ is counting rate in the same energy window with the background count (counts $\left.\sec ^{-1}\right), P_{i}\left(E_{i}\right)$ is emission probability of gamma energy, $E_{i}, m_{s}$ is mass of the sample (g) and $\mathrm{C}$ is the activity concentration of the reference materials in $\mathrm{Bq} / \mathrm{g}$.

\section{E. Detection limit of NaI(Tl) for measurement of $40 \mathrm{~K}$, 226Ra and 232Th}

The detection limit, $L_{D}$ is defined as the "true" net signal level below which there may not be any detection of radiation. $L_{D}$ according to [19] is expressed as;

$L_{D}=2.71+4.65 \sqrt{\mu_{B}}$

Where, $\mu_{B}$ is background signal level.

By equating (2) and (3), it can be shown that $\mathrm{L}_{\mathrm{D}}$ of measuring ${ }^{40} \mathrm{~K},{ }^{226} \mathrm{Ra}$ and ${ }^{232} \mathrm{Th}$ in pulverized samples with the $\mathrm{NaI}(\mathrm{Tl})$ can be given by (4) [19].

$$
L_{D}=\frac{1}{m_{S} \varepsilon_{i}\left(E_{i}\right) P_{i}\left(E_{i}\right)}\left(\frac{2.71}{T}+4.65 \sqrt{\frac{C_{B}}{T}}\right)
$$

Where, $\mathrm{C}_{\mathrm{B}}$ is background count rate in the channels of interest (counts $\sec ^{-1}$ ), $\mathrm{T}$ is counting time $(\mathrm{s}), \varepsilon_{I}\left(E_{i}\right)$ is the counting efficiency for gamma energy of interest ( $\mathrm{cpc} \mathrm{Bq}{ }^{-1}$ ), $P_{i}\left(E_{i}\right)$ is the emission probability $\left(\mathrm{sec}^{-1} \mathrm{~Bq}^{-1}\right), \mathrm{m}_{\mathrm{s}}$ is mass of the background material $(\mathrm{kg})$.

Distill water was counted for $10800 \mathrm{~s}, \mathrm{C}_{\mathrm{B}}$ is calculated to be $0.03,0.00$ and $0.05 \mathrm{cps}$, for channels corresponding to $1460 \mathrm{keV}$ (for ${ }^{40} \mathrm{~K}$ ), $1760 \mathrm{keV}$ (for ${ }^{226} \mathrm{Ra}$ ) and $2615 \mathrm{keV}$ (for ${ }^{232} \mathrm{Th}$ ) respectively. These values, as well as those of $\varepsilon_{I}\left(E_{i}\right)$ and $P_{i}\left(E_{i}\right)$ were substituted in (4) and the $L_{D}$ were calculated and results recorded. These calculations assume a sample mass of $200 \mathrm{~g}$ which is the average mass of the pulverized samples analyzed in this present study.

\section{F. Validation}

To validate the reliability of the detector, other secondary samples, RGMIX1 and RGMIX2 were formulated. RGMIX1 and RGMIX2 were secondary calibration materials prepared in the laboratory by mixing the three reference samples RGTh, RGU and RGK in different proportions. RGMIX1 was made up of $116.8 \mathrm{~g}$ of RGTh, $107.2 \mathrm{~g}$ of RGU and $103.4 \mathrm{~g}$ of RGK. RGMIX2 was made up of $327.5 \mathrm{~g}$ of RGTh, $329.4 \mathrm{~g}$ of RGU and $322.0 \mathrm{~g}$ of RGK. In terms of radiological composition, the products RGMIX1 and RGMIX2 are considered to be more analogous to most geological materials than any of the three primary reference materials from which they were formulated. These secondary samples were sealed in used containers similar to the ones used for any other samples and also kept for about one month to achieve equilibrium between ${ }^{226} \mathrm{Ra}$ and its decay products. The RGMIX1 and RGMIX2 were counted for $10800 \mathrm{~s}$, but even then, only three gamma lines were resolvable without much interference. The gamma lines were $1460 \mathrm{keV}, 1764 \mathrm{keV}$ and $2615 \mathrm{keV}$.

\section{G. Calculation of Activity concentration}

The activity concentrations, $\mathrm{C}$ in $\mathrm{Bqkg}^{-1}$ were calculated from the decay and isotropic data along with the elemental concentration values $C_{o}$ provided in the reference materials preparation certificate using (5) [19].

$$
C=\frac{C_{o} N_{A} \lambda . I}{M_{W}}
$$

Where: NA is Avogadro number $\left(6.023 \times 1023\right.$ mole $\left.^{-1}\right)$; $\lambda$ is decay constant $\left(\mathrm{sec}^{-1}\right)$; $\mathrm{I}$, is relative isotropic abundance; MW is molecular weight $\left(\mathrm{g} \mathrm{mole}^{-1}\right)$.

The results obtained from the samples and certified reference materials were substituted in the comparison method formula to get activity concentrations of the primordial radionuclides using (6) [20].

$$
\frac{A_{\text {sample }}}{A_{\text {std }}}=\frac{C R_{\text {sample }}-C R_{\text {Bgd }}}{C R_{\text {std }}-C R_{\text {Bgd }}}
$$

Where: $\mathrm{A}_{\text {sample }}$ is Activity concentration of the sample $\left(B q \mathrm{~kg}^{-1}\right) ; \mathrm{A}_{\mathrm{std}}$ is Activity concentration of the standard $\left(B q \mathrm{~kg}^{-1}\right) ; \mathrm{CR}_{\text {sample }}$ is count rate of sample (counts $\mathrm{sec}^{-1}$ ); 
$\mathrm{CR}_{\mathrm{Bgd}}$ is count rate of Background (counts $\mathrm{sec}^{-1}$ ); $\mathrm{CR}_{\text {std }}$ is Background of standard (counts $\mathrm{sec}^{-1}$ ); $\mathrm{CR}_{\mathrm{Bgd}}$ is count rate of Background (counts sec ${ }^{-1}$ ).

\section{RESULTS AND DISCUSSION}

Table I depicts the result of the detector resolution. The resolution of the detector was calculated to be $7.8 \%$ of ${ }^{137} \mathrm{Cs}$ which proved to be good for the $\mathrm{NaI}(\mathrm{Tl})$ detector.

TABLE I RESULT OF DETECTOR RESOLUTION

\begin{tabular}{ccccc}
\hline \hline Centroid channel & FWHM & $\begin{array}{c}{ }^{137} \text { Cs energy } \\
(\mathrm{KeV})\end{array}$ & $\begin{array}{c}\text { Resolution } \\
(\mathrm{KeV})\end{array}$ & $\begin{array}{c}\text { Resolution } \\
\left(\% \text { of }{ }^{137} \mathrm{Cs}\right)\end{array}$ \\
\hline 77 & 6 & 662 & 51.57 & 7.8 \\
\hline
\end{tabular}

Table II shows the calculated and measured values of activity of three radionuclides in the formulated samples (RGMIX1 and RGMIX2), and the counting efficiency of the detector. From the results obtained, it was observed that the counting efficiency depends on gamma-ray energy.

\begin{tabular}{cccccc}
\multicolumn{5}{c}{$\begin{array}{c}\text { TABLE II EMISSION PROBABILITY, COUNTING EFFICIENCY } \\
\text { AND DETECTION LIMIT LD OF NaI(TI) WITH IAEA } \\
\text { STANDARD MATERIALS }\end{array}$} \\
\hline $\begin{array}{c}\text { Reference } \\
\text { materials }\end{array}$ & $\begin{array}{c}\text { Gamma-ray } \\
\text { energy } \\
(\mathrm{keV})\end{array}$ & $\begin{array}{c}\text { Emission } \\
\text { probability } \\
\text { (IAEA, 1992) }\end{array}$ & $\begin{array}{c}\text { Counting } \\
\text { efficiency } \\
\left(10^{-2} \mathrm{Cps} / \mathrm{Bq}\right)\end{array}$ & $\begin{array}{c}\text { Source } \\
\text { Nuclide }\end{array}$ & $\begin{array}{c}\mathrm{LD} \\
\left(10^{-2} \mathrm{~Bq} / \mathrm{kg}\right)\end{array}$ \\
\hline RGK-1 & 1460 & 0.1066 & 1.58 & ${ }^{40} \mathrm{~K}$ & 11.6 \\
\hline RGU-1 & 1764 & 0.1517 & 0.51 & ${ }^{214} \mathrm{Bi}$ & 10.0 \\
\hline RGTh-1 & 2615 & 0.3585 & 0.28 & ${ }^{208} \mathrm{Tl}$ & 12.5 \\
\hline
\end{tabular}

Table III displays the measured, calculated activity and percentage deviation in RGMIX1and RGMIX2.

TABLE III MEASURED AND CALCULATED ACTIVITY IN RGMIX1AND RGMIX2

\begin{tabular}{|c|c|c|c|c|c|c|}
\hline \multicolumn{7}{|c|}{ Activity (Bq) } \\
\hline & RGMIX1 & & & RGMIX2 & & \\
\hline Element & Calculated & Measured & \% Dev. & Calculated & Measured & $\%$ Dev. \\
\hline${ }^{40} \mathrm{k}$ & 4.20 & 4.22 & 0.48 & 5.50 & 5.58 & 1.4 \\
\hline${ }^{226} \mathrm{Ra}$ & 1.75 & 1.78 & 1.71 & 1.19 & 1.24 & 4.0 \\
\hline${ }^{232} \mathrm{Th}$ & 1.02 & 1.08 & 5.88 & 1.15 & 1.10 & 4.4 \\
\hline
\end{tabular}

Fig. 1 and 2 illustrates the comparison of calculated and measured activities of radionuclides in RGMIX1 and RGMIX2, with both figures showing no significant difference between the calculated and measured activities of the formulated samples.

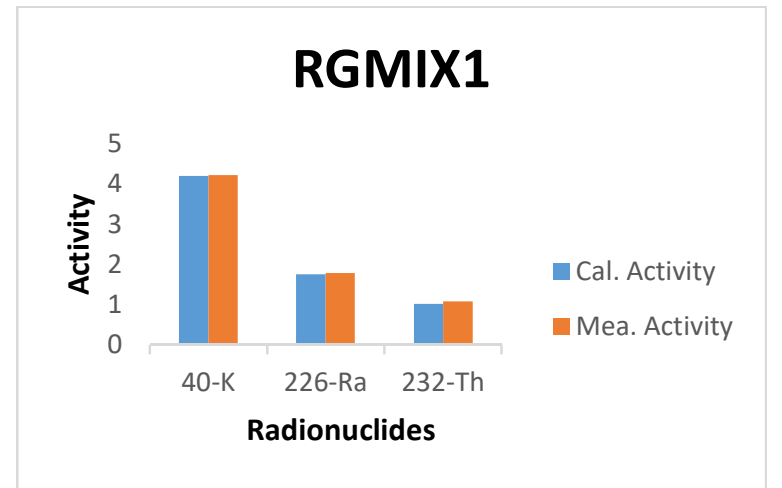

Fig. 1 Comparison of calculated and measured activities of radionuclides in RGMIX1

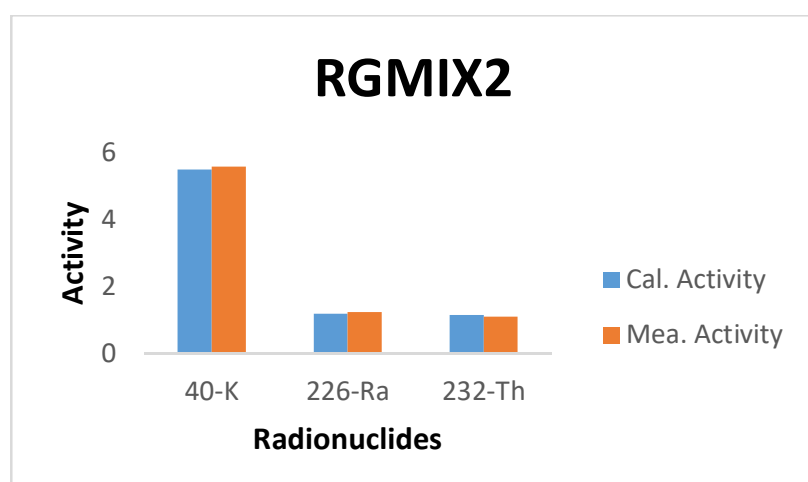

Fig. 2 Comparison of calculated and measured activities of radionuclides in RGMIX2

\section{CONCLUSION}

The need to validate the reliability of the detector used in gamma spectroscopy in the Radiation and Health Laboratory, Department of Physics, Federal University of Agriculture Abeokuta, South Western Nigeria lead to the formulation of two secondary calibration materials, RGMIX1 and RGMIX2. Working procedures implemented in the validation to determine the detector's resolution, detection limit and calibration have been elaborated. The measurements carried out on the secondary calibration materials using the $\mathrm{NaI}(\mathrm{Tl})$ detector shows that a good correlation exists between the measured and calculated activities of the three radionuclides $40 \mathrm{~K}, 226 \mathrm{Ra}$ and $232 \mathrm{Th}$ in the formulated calibration materials. The results from this work shows that the detector system is suitable gamma spectrometry, it is of optimal performance and will give quality measurements when used for quantitative determination of radionuclides in environmental samples.

\section{ACKNOWLEDGMENT}

The authors are thankful to Mr. Macaulay for his unflinching support during the course of this work. 


\section{References}

[1] L. Bamidele, "Measurement of ionizing radiation level in a high altitude town of Imesi-Ile, Osun State Southwestern Nigeria," Env. Res. J., vol. 7, no. 4, pp. 79-82, 2013.

[2] A. Ayham, A. O. Abdul-Jabbar, S. J. A. Awatif and H. A. Asia, "Determination of Natural Radioactivity by Gamma Spectroscopy in Balad Soil, Iraq," $A d v$. App. Sci. Res., vol. 7, no. 1, pp. 35-41, 2016.

[3] S. Klassen, "The photoelectric effect: reconstructing the story for the Physics classroom," Sci. Edu., vol. 20, no. 7-8, pp. 719-731, 2011.

[4] E. P. James, "The Compton effect--Compton scattering and gamma ray spectroscopy," 401 Nielsen Physics Building, University of Tennessee. Knoxville, Tennessee. 37996-1200, 2015, pp. 1-37.

[5] M. Ron, "Introduction of gamma-ray spectrometer," Ficom Systems Ltd., 2016, pp. 1-61.

[6] E. D. Stephen, and W. M. William, "Experimental efforts and results in finding new heavy scintillators," Proceedings of the CRYSTAL 2000 International Workshop on Heavy Scintillators for Science and Industrial Applications, Chamonix, France, Sept. 22-26, 1992.

[7] G. F. Knoll, "Radiation detection and measurement," $3^{\text {rd }}$ Edn. John Wiley and Sons Inc. (1999) ISBN 0-471-07338-5.

[8] T. Yangida, "Inorganic scintillating materials and scintillation detectors," Proc. Jpn. Acad. SerB, Phys. Bio. Sci., vol. 94, no. 2, pp. 75-97, 2018.

[9] G. Michal, M. Marek, D. Wolski and P. Bertrand, "Comparative study of large $\mathrm{NaI}(\mathrm{Tl})$ and $\mathrm{BGO}$ scintillators for the EURopean Illicit TRAfficking Countermeasures Kit Project.," IEEE Trans. Nuc. Sci., vol. 53, no. 3, pp. 1737-1743, 2006.

[10] K. Junhyeok, P. Kyeongjin, H. Jisung, K. Hojik, K. Jinhwan, K. Hyunduk, et al. "Efficient design of a $2 \times 2$ inch $\mathrm{NaI}(\mathrm{Tl})$ scintillation detector coupled with a SiPM in an aquatic environment," Nuc. Eng. Tech., vol. 51, pp. 1091-1097, 2019.

[11]C. Papastfanou, "Measurement of naturally occurring radionuclides with several detectors: advantages and disadvantages," Austral-Asian J. Canc., vol. 7, no. 4, pp. 267-280, 2008.

[12]A. Dalal, "Calibration of the absolute efficiency of well-type $\mathrm{NaI}(\mathrm{Tl})$ scintillation detector in 0.121 $1.408 \mathrm{MeV}$ energy range," Science and Technology of Nuclear Installations. 1-6, 2018, Article ID 6432380.

[13]E. Joseph, and R. Nasiru, "Geometry correction in efficiency of a Sodium Iodide (Thallium Activated), NaI(Tl) Detector," Adv. App. Sci. Res., vol. 4, no. 1, pp. 400-406, 2013.

[14] R. Nafaa, "Gamma Ray Spectrometry," practical information compilation, 2016, 1-79. https://www.researchgate.net/publication/2595335 88 Gamma Ray Spectrometry.
[15] S. A. Amin, "Assessment of naturally occurring radioactive materials (NORM) in the oil drilling mud of Az Zubair oil field, Basra, Iraq," Env. Earth Sci., vol. 75, pp. 769, 2016. DOI: 10.1007/s12665016-5564-y

[16] ORTEC. Revision D. DigiBase User's Manual. Advance Manual Revision Measurement Technology Inc. 2014; 931003.

[17]H. Florou, G. Trabidou, and G. Nicolaou, "An assessment of the external radiological impact in areas of Greece with elevated natural radioactivity," J. Env. Rad., vol. 93, pp. 74-83, 2007.

[18] M. Q. Hiwa, "Comparison of energy resolution and efficiency of $\mathrm{NaI}(\mathrm{Tl})$ and $\mathrm{HPGe}$ detector using gamma-ray spectrometry," J. Phy. Chem. Funct. Mat., vol. 3, no. 1, pp. 24-27, 2020.

[19]A. O. Mustapha, "Assessment of human exposures to natural sources of radiation in Kenya," Ph.D. Thesis (Physics). University of Nairobi. Kenya, 1999.

[20] A. S. Okedeyi, A. M. Gbadebo, T. A. Arowolo, and P. Tchokosa, "Gamma radioactivity levels of rock and soil and their corresponding external exposures in navy quarry site, Abeokuta, South-Western Nigeria," Asian J. App. Sci., vol. 5, pp. 506-513, 2012. 